\title{
Peter Emerson: From Majority Rule to Inclusive Politics. Electing a Power-Sharing Coalition
}

\author{
Springer International Publishing, 2016, XXVI+146 p., ISBN 978-3-319-23500-4
}

\section{ROMAN CHYTILEK ${ }^{1}$}

The newly published book of Northern Irish political scientist and activist, Peter Emerson, From Majority Rule to Inclusive Politics. Electing a Power-Sharing Coalition is a very personal and passionate defence of consensual voting procedures. I liked reading the preface, where the author nicely and very honestly discussed his relationship to what he was going to discuss, along with clearly declaring his normative position to the subject.

So what is Emerson for? He is for maximum power-sharing, all-party coalitions for executives and proportional representation in legislatures. Entrusting legislatures with maximal power, he devises special voting procedure based on preferential voting, the matrix vote, to elect the executive during one ballot with multiple issues (and options) being voted simultaneously. In case of the executive, individual executive portfolios, preferably even that of the prime minister, are allocated in that way. Emerson contrasts his proposals with the current trend of majoritarianism, in which binary yes-no, win-lose elections are typical, and a subsequent number of decisions are left to the single figure of prime minister, whom he calls an "elected dictator". He is also not satisfied with the current uses of decision rules based on proportional representation, in which he regards the forming of the executives to be very slow. Emerson advocates uses of non-binary options for the referendums as well. His subtle argument that especially when the status quo option is the winner of the binary referendum ballot, the "status quo" is only rarely left unchanged in the form in which it was voted on, is inspiring and begs to be a subject of further empirical research. The book is also full of examples explaining the mechanics of electoral rules that Emerson advocates with such ubiquitous passion.

\footnotetext{
${ }^{1}$ Fakulta sociálních studií, Masarykova univerzita, Joštova 10, 60200 Brno / Department of Political Science, Faculty of Social Studies, Masaryk University, Brno, Czech Republic. E-mail: chytilek@apps.fss.muni.cz.
} 
To start with some substantive critique, it seems to me that the book should provide much better theoretical analysis of ballots with multiple issues (doesn't matter whether with binary and/or non-binary options) which seem to be the central democratic innovation proposed by Emerson. The problem with them is that the voters have nonseparable preferences about the issues and the set of decisions which is achieved as a result of the simultaneous ballot may be even Condorcet loser and/or Pareto-dominated by any other combination of outcomes (Lacy and Niou 2000). Lacy and Niou show that it is only an optical illusion that multiple simultaneous ballots (with or without multiple options voted for) lead to socially more desirable outcomes. They also show that in legislatures (as contrasted to general electorates) the problem of nonseparable preferences can be well resolved through sequential voting and vote trading. This is in my eyes a very serious argument in favour of sequential, instead of simultaneous, voting when dealing with multiple issues. Otherwise we are running a serious risk of arriving through efficient, representative and consensual procedure to the result which is not consensual at all. Yet the book is silent about it.

Unfortunately the book doesn't generally fare too well when it comes to acquainting the reader with the previous research in the field. The lament about the perils of majoritarianism with the spiral of division, long-term antagonism, violence and the increasing dead toll in divided societies isn't new, yet references to the work of Reynolds, Reilly, Sisk, Boogards and others - and much more importantly, to their substantive arguments - are missing. Wasn't it for this omission of potentially relevant information, the author would be able to make more empirically rich arguments for his cause without the need to stick with the iterative mantra of "millions people dead as a result of majoritarianism" argument. Moreover, the level of empirical detail in the book is clearly insufficient for such a very strong conclusion. True, there are tens of illustrative examples of shortcomings of majoritarianism which is judged by its worst examples by Emerson. On the contrary, he is much more relaxed to his own proposals, bringing forth their best intensions in the hypothetic examples of how to use them. His line of reasoning is that while politicians abuse majoritarian rules, they value the consensual ones and use them to achieve socially desirable results. Personally I find the indications of the hypothetical "pre-decision" of the author that consensual rules exclude the attempt to abuse them to be quite unrealistic.

A little less systematic than usual inquiry of the author also led me to some doubts about possible confusion between correlation and causation at some points of his argumentation. He is right that proportional systems, for example, are not the fastest ones in terms of government formation; however the problem may not always be related to portfolios but, for instance, to policy formulation. Emerson's way of creating an executive is time-efficient in terms of office-seeking logic, but can have quite ambivalent consequences from the point of view of the subsequent steadfastness of the chosen government and policy considerations. The book also 
posed a significant challenge for the author in terms of the generalisability of his suggestions. While in some parts it is relatively strictly placed as a remedy for conflict and divided societies, in other contexts it suggests conviction about their universal suitability.

To conclude, although the book probably does not exhibit the usual level of theoretical depth and rigorousness typical for comparative research on electoral systems, one has to agree with the foreword of Ian McLean that it offers viable alternative to the winner-take-all logic of that kind where the democracy can still thrive. For me, the reading was primarily about thinking about contexts where it is actually better to use non-binary voting. In the department of thought provoking ideas is Peter Emerson clearly a pertinent choice!

\section{References}

Lacy, Dean, and Emerson M. S. Niou. 2000. “A Problem with Referendums.” Journal of Theoretical Politics 12(1): 5-31 